\title{
Open access: are we there yet? - the case of Stellenbosch University, South Africa
}

\author{
Reggie Raju ${ }^{1}$, Ina Smith ${ }^{2}$, Paulette Talliard ${ }^{3}$ and Hilton Gibson ${ }^{4}$ \\ Library and Information Service, Stellenbosch University \\ rraju@sun.ac.za
}

Received: January 2012

Accepted: September 2012

It is often acknowledged that African and other developing countries have a desperate need for quality scholarly information to advance their research output and to make a contribution to the world of scholarly communication. In terms of Africa, South Africa is the most significant producer of research output in sub-Saharan Africa and has, therefore by default, become a beacon of hope for Africa in the area of research production. This case study focuses on the contribution of Stellenbosch University (SU) to the African research agenda through making its research output available via two different publishing models. The first model is the hosting and preservation of its research output via an institutional repository (the green route to open access). The second model is hosting and publishing open access journals, following one of two 'streams' in the gold route. In this paper, the authors contextualize open access. The two publishing models in support of the Strategic Plan for the Environment of the Vice Rector (Research) are discussed as it applies to SU. The Library's adoption of the role of 'publisher' is also examined. In the case of SU, Open Journal Systems (OJS) is the software of choice for hosting open access online journals. The paper provides background on OJS, and also discusses the significance of OJS publishing for the University and its researchers. It concludes with the view that despite the perceived success of the Library and Information Service in making available research output in open access format, there are still many challenges that need to be overcome, and that this process is a continuous one and should remain so in order to continuously take advantage of opportunities offered by evolving technology.

Keywords: Developing countries; institutional repositories; open access; open access information; open access journals; Open Journal Systems (OJS)

\section{Introduction and background}

Libraries are rapidly developing along a new trajectory which is extensively influenced by technology. The library, in its traditional format as a warehouse of information is fast being transformed into a facilitator of information. In this role as facilitator, it is functioning as a conduit bringing together the vast ocean of information that is now available in digital format. Unfortunately, despite this exponential growth of trusted and relevant digital information, there is a scarcity of information as exorbitant subscriptions make it unaffordable - especially to the developing world. Researchers spend vast amounts of time conducting and recording their research only for publishers to attach exorbitant costs to that research making it inaccessible to the information seeking research community, especially

\footnotetext{
${ }^{1}$ Reggie Raju (PhD), who is the corresponding author, is the Director: Client Services, Library and Information Service, Stellenbosch University.

${ }^{2}$ Ina Smith is the eRepository Manager, Library and Information Service, Stellenbosch University.

${ }^{3}$ Paulette Talliard is a Library Assistant, Library and Information Service, Stellenbosch University.

${ }^{4}$ Hilton Gibson is a Systems Administrator, Library and Information Service, Stellenbosch University.
} 
researchers from the developing world. The tragedy is that the developing world is in desperate need of this research information to find solutions to the myriad of problems that beset their development. This assertion is corroborated by OndariOkemwa (2007) who points out that the free flow of ideas and information is vital to the process of scientific inquiry, and in turn to the ability to address economic, environmental and social development issues both in the sub-Saharan Africa region and globally.

Despite this desperate need for trusted and relevant information for African development, as pointed out by Nwagwu and Ahmed (2009: 90), sub-Saharan Africa has not made significant contribution to the world's research output. In fact, Africa has supplied only $0.7 \%$ of the output with a very large percentage of that coming from South Africa (Nwagwu and Ahmed 2009; Ondari-Okemwa 2007). This statistic may well be a true reflection of scientific activities in Africa. However, there is sufficient evidence (Ondari-Okemwa 2007; Nwagwu and Ahmed 2009; Adams, King, and Hook 2010; Kotecha, Walwyn, and Pinto 2011; Tise 2011) to suggest that the low profile of scientists in Africa is attributed to poor access to scientific publications. South Africa occupies the paradoxical position in the arena of research publishing of being a dwarf internationally and a giant on the African continent. Given that South Africa is the most significant producer of research output in sub-Saharan Africa, by default, it has become a beacon of hope in Africa in the area of research production. Therefore, it is incumbent upon South African researchers and research institutions to fast track its transformation to open access in the pursuit of sharing its research output with the rest of Africa.

This transformation must be viewed against the desperation articulated by Akst and Jensen (2001) who state that a remarkable characteristic of mass starvation is how rare it is in free countries. Unfortunately, Africa today is in the grip of a famine, although it only sometimes involves not having enough to eat: "The continent is afflicted instead by an information famine, one with consequences not so very different from a severe shortage of food. Growth is stunted. People die. The future dims" (Akst and Jensen 2001).

Stellenbosch University (SU) is considered to be one of the leading research universities in South Africa and in Africa. Therefore, it is imperative that every effort is made to share the research output of SU with the rest of South Africa, the continent and the world at large.

This paper discusses initiatives taken by Stellenbosch University to develop its institutional repository in its quest to share research with the widest possible audience. Further, the University has been experimenting with open source software to 'publish' journals in an open access forum. One of the prerequisites for participation in the open access publishing pilot project is that there must be some affiliation, within the editorial board, with the University. Currently, the editors-in-chief (in the main) are members of staff of Stellenbosch University. This paper also 
introduces to other academic institutions in South Africa and on the continent the possibility of 'publishing' quality peer-reviewed journals using open source software. This route makes the publishing process inexpensive and opens access to critical and relevant content to African researchers. This practice of the Library at SU, that is, acting as a publisher stimulates the growth of a new chapter in African librarianship.

This paper examines, albeit very briefly, the motives for the initiation of the open access movement and the definition of open access. It then discusses the two significant open access models, namely, the green route and the gold route. This discussion serves as the basis for the examination of open access practices at Stellenbosch University. An area of focus in this discussion is the pilot project aimed at publishing journals using Open Journal Systems (OJS) and the significance of such a publishing model for Stellenbosch University and research institutions in general.

\section{Methodology}

This paper adopts the qualitative research approach of a case study, examining specifically the initiatives of the Stellenbosch University Library and Information Service. The choice of methodology is aligned with the views of Gorman and Clayton (2005: 47) who define a case study as an investigation of an "entity on the assumption that it is possible to derive knowledge of the wider phenomenon from intensive investigation of a specific instance or case".

The case study approach is, for the most part, limited to a single setting, subject or event which projects an aura of containment in space and time. Fouche (2005: 272) goes on to add that a case study is as an analysis of a 'bounded system' - bounded by time and/or place. The emphasis is on a single unit. In this paper, the authors examine the activities of Stellenbosch University Library and Information Service as a single unit and in particular its adoption of open access principles and the development of strategies to accelerate the growth of its open access activities and, in some instances, take the lead in testing and implementing new methodologies of opening access to scholarly communication.

The authors also take their cue from Lindegger (2006) and Blaxter, Hughes and Tight (2006). Lindegger (2006: 456) makes the assertion that case studies are intensive investigations of organisations and are usually descriptive in nature providing rich information on a particular situation. Blaxter, Hughes and Tight (2006: 73-74) are of the view that a case study might be the researcher's place of work (as is the case in this paper) or another institution or organisation with which they have a connection. They go on to point out that case studies are often used to illustrate problems or indicate good practice. The authors are of the view that the open access activities at Stellenbosch University are an indication of good practice to be shared with others. Open access is considered to be 'a public good'. Hence activities 
associated with this 'public good practice' should be shared to encourage its growth and development. Further, open access activities are fast becoming a significant driver in academic librarianship.

\section{Status of research output in Africa}

As indicated above, sub-Saharan Africa has not made significant contribution to the world's research output. The low profile of the research output from Africa is exacerbated by the fact that research conducted in Africa is not easily accessible to the international audience as the dissemination of African research content is severely prejudiced as international publishers tend to be guided by profit margins. This prejudice relegates Africa further into the status of being a silent and invisible contributor to research production. Compounding the 'access drought' is the fact that research conducted in Africa and published in international journals are not accessible, due to financial constraints, to those African researchers and other communities that need it the most.

The 'access drought' negates the African research agenda which is to seek African solutions for Africa's sustainable development. This research agenda which revolves around drought, food security, poverty, health, desertification, agriculture, HIV/AIDS, conflict resolution, science policy, capacity building, entrepreneurship, technology, markets, and leadership in Africa is compromised by the lack of access to authentic and relevant information to support African research. This prejudicial situation can be addressed by employing methodologies and processes (such as that of OJS) that will allow for the free flow of scholarly literature to and from developing countries (Africa Institute of South Africa 2011; Zvavanyange 2012).

An examination of research management tools such as the Web of Science (see Ondari-Okemwa 2007) and SCOPUS, show the gulf in research production between South Africa and the rest of the African countries.

As reflected in Figure 1, in the period 1999-2009, Africa produced just over 170000 items that appeared on the SCOPUS database with South Africa producing $66 \%$ more than the second highest producer, Nigeria. However, the more significant issue is 'what percentage of this research output is available to researchers on the African continent?'. How much of this research is locked away in exorbitant subscription costs? Libraries, as significant contributors to the generation of new knowledge, have an obligation to strengthening the African higher education space by developing forums that will improve access to information for researchers to manipulate in the generation of new knowledge. 


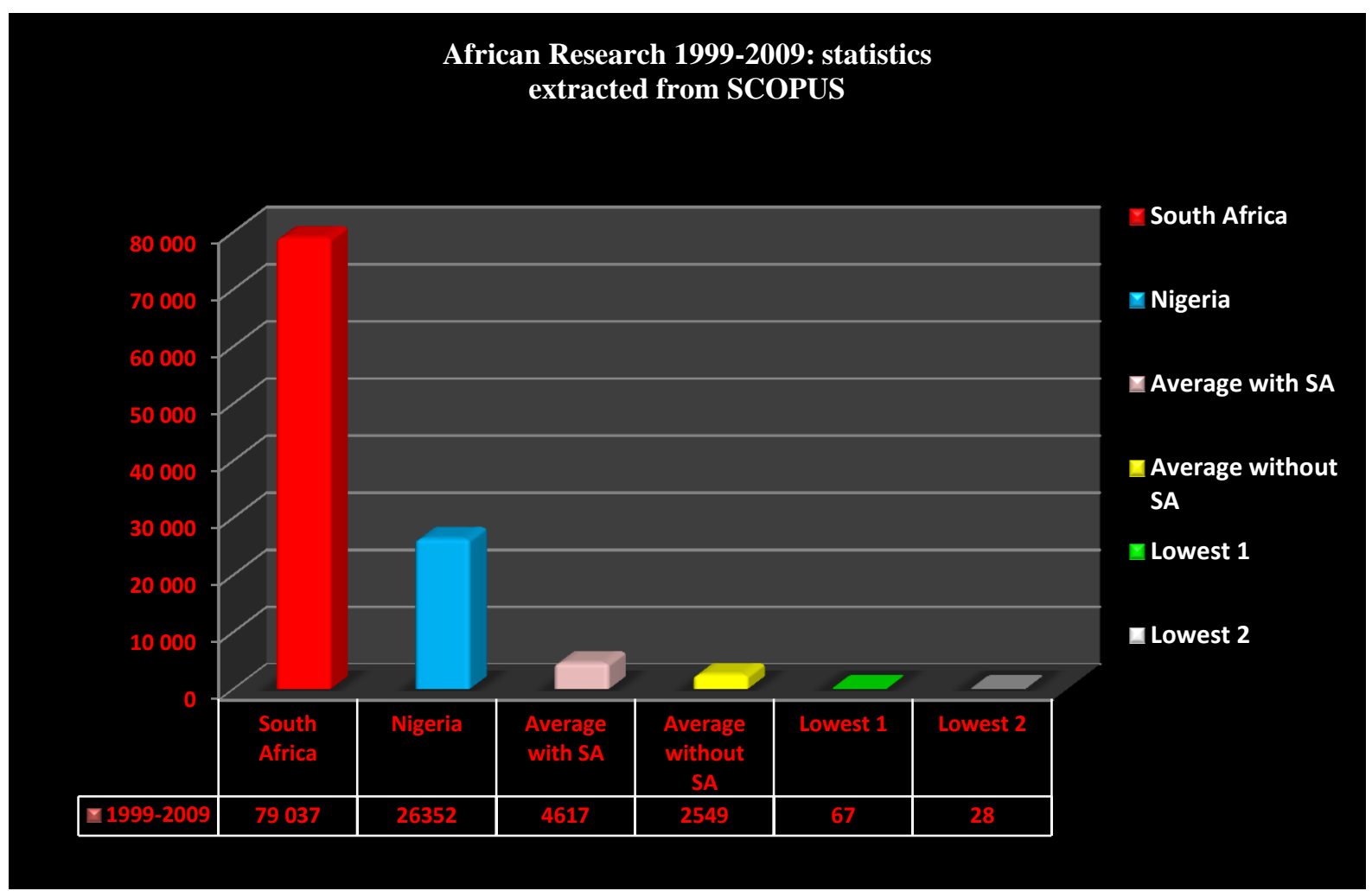

Figure 1

\section{$4 \quad$ Contextualising open access}

In 2007 Peter Lor posited his explanation for the initiation and growth of the open access movement. His view was that the rise of the open access movement was as a result of the convergence of an economic crisis, a moral crisis and an enabling technology. Firstly, the economic factor is one of spiralling prices. The cancellation of journal subscriptions year after year is becoming the norm in academic libraries, and so too are drastic cut backs on monograph purchases in order to maintain what is seen as essential journal titles. In developing countries, as pointed out by Lor (2007), the situation is catastrophic with many large universities in sub-Saharan Africa holding just a few hundred serial titles, many of which they receive free of charge.

The second factor is a twofold moral crisis. The first issue is the inability of researchers in developing countries to gain access to the world's science and scholarship. The continued reference to the 'digital divide' is not restricted to the technology divide, but also to a content or knowledge divide. The second issue is a growing sense that the relationship between authors, journal publishers and users is out of balance and unfair. There is a willingness by authors to submit their research free of charge and the willingness of editors and referees to peer-review the research also without a fee attached. Scholars publish their research in peerreviewed journals for professional gain. The costs borne by subscribers are generated through the publication and distribution processes. 
The third factor is the advent of the Internet. This digital technology is used both to control and to enhance access to scholarly literature. Digital technology seems at first sight to offer significant cost savings by reducing set-up costs as well as marginal costs relating to making scholarly literature accessible.

\section{$5 \quad$ Defining open access}

As alluded to, open access to scholarly communication is the explicit removal of price barriers (such as, subscriptions, licensing fees, pay-per-view fees) and permission barriers (such as, most copyright and licensing restrictions) to the end user. This definition is corroborated by Jeffrey (2006) who points out that open access ensures that "electronic scholarly articles are available freely at the point of use" - highlighting the 'freeness' of scholarly communication to the end user.

\section{$6 \quad$ Publishing models}

Open access publishing is dominated by two models. The first model is that of institutional repositories. This model is commonly referred to as the 'green road' in open access publishing with two significant objectives, namely, openly sharing research output of the institution and digital preservation. The second model is publishing directly with an open access publisher. This is generally referred to as the 'gold road'. Authors here publish their research articles directly in an open access journal.

\subsection{Green road publishing: institutional repositories}

Institutional repositories have been the forerunner of the open access movement. Lynch (2003) points out that the "development of institutional repositories emerged as a new strategy that allows universities to apply serious, systematic leverage to accelerate changes taking place in scholarship and scholarly communication...". Lynch (2003) defines institutional repositories as a set of services that a university offers to members of its community for the management and dissemination of digital materials created by the institution and its community members. These digital materials include, inter alia, e-prints, e-theses, data sets, technical reports and working papers. Essentially, an institutional repository is about organisational commitment to the stewardship of these digital materials, including long-term preservation where appropriate, as well as organisation and access or distribution. The synergic relationship between publication of research output and universities influences the definition of institutional repositories. However, institutional repositories need not be confined to universities.

There are two significant objectives influencing the growth and development of institutional repositories. These two objectives underpin Crow's (2002: 4) definition of an institutional repository in which he posits that repositories are "digital collections capturing and preserving the intellectual output of a single... university community". 
The first objective is to capture the output of the institution and to share it with the widest possible audience. In terms of this objective, it is important that researchers deposit their research output, including research articles, into the repository. In terms of populating the repository with published research articles, self-archiving is the preferred method. 'Author self-archiving' is the electronic posting, without publisher mediation, of author-supplied research. In practice, such self-archiving encompasses both the posting of pre-prints and (in many instances) published papers (post-prints) by individual researchers on personal web sites. Policies of traditional publishers concerning author self-archiving of published papers vary, as does the stringency with which the policies are enforced. The response of academic authors themselves to such policies runs the gamut from strict adherence to utter indifference. In the process of self-archiving, authors play an important role in content recruitment for repositories and become key partners in collection development. Gozetti (2006) asserts that self-archiving should be mandatory for sustainable growth of institutional repositories.

The second objective is preserving the intellectual output of the institution. Gozetti (2006: 23) asserts that "the issue about addressing long-term access to content is very strong in the literature and preservation is perceived as one of the key issues that can determinate the success of IR [institutional repositories] ... it requires proactive management and long term planning". There are a number of initiatives that support long term preservation.

The authors are of the view that planning is imperative for preservation. For example, research articles that are submitted to a repository must comply with certain file formats that allow for continued accessibility. The objective is to preserve material by converting it into a digital object format in such a way that the digital objects created may be read and understood by future technology systems. File formats such as 'pdf/a', open documents and media codec (coder decoder) facilitate long term preservation. Further, in keeping with long term preservation, the authors argue that digitized objects must use an uncompressed bit stream (the file that is in binary format) for storage. Also, material to be submitted to a repository must use open published digital format standards and the concomitant metadata schemas.

The development of institutional repositories 'kick-started' the open access movement. Not too much later came the drive to publish directly in open access journals or to publish via the 'gold road'.

\subsection{Gold road publishing: open journals}

Open Access Journals (or OA journals) are electronic-based journals that make their published content available freely to all immediately upon publication. They differ from traditional journals (toll access or subscription journals) in that their businessmodel is not based on subscriptions, that is, end users are not charged fees to access the journal's content. 
The open access journal publishing model, in the opinion of Crow (2002), has turned the conventional commercial model for journal publication on its head. There are two streams in terms of this model. The first stream is publishing with established 'for profit' vendors such BioMed Central (BMC). The second stream is publishing with 'not for profit' organisations including organisations using open source software such as Open Journal Systems (OJS). The second stream is relatively new and is fast gaining momentum. In terms of the first stream, costs are incurred at the initial stages of the supply chain, instead of paying subscriptions at the end of the supply cycle, making the journal content available online free of charge. Universities, already investing heavily in the traditional publication model by providing authorship, peer-reviewing and editorship free of charge, and often paying page fees, have been relinquishing copyright and earning no royalties. Furthermore, universities have to then buy back the publications at ever increasing subscription costs which are steadily putting scholarly publications out of the reach of even the wealthiest universities (Swan 2006).

The significant benefit of the open access model is that the journals would be funded by author fees paid once an article is accepted for publication. The journal would then be available, full text online, free of charge. Essentially, the open access journals publication model offers online access, free of charge, to peer-reviewed journal articles. As pointed out by Swan (2006), open access publishing is not vanity publishing or uncontrolled posting of content onto the web, but is a form of peerreviewed scholarly publishing, following a different business model.

Open access scholarly publishing offers the potential for democratic access to research knowledge, opening-up the conventional scholarly market (which is targeted primarily at a peer group of fellow-scholars) to include a much wider range of readers and stakeholders in both the public and private sectors.

In terms of the second stream of the open access journal publishing model, librarians are taking up the challenge of assuming a new role. This new role is that of a publisher of scholarly information for public good. Research conducted by the Association of Research Libraries (ARL) revealed that there are member libraries that provide publishing services. These libraries use a combination of publication tools such as Open Journal Systems and the Berkeley Electronic Press (bepress) (Hahn 2008).

Discussions in the literature on libraries acting as publishers have concentrated on the applicability, sustainability and scalability of providing such a service. Advocates of open access publishing and librarians are confident about the applicability. Xia (2009: 373) claims that research has found that scholars have a positive attitude towards cooperating with librarians and are willing to take the responsibility of organising an editorial process for the quality control of publications. Peer-review is considered a necessary procedure for assessment of articles, as has traditionally been the case for scholarly journals. An easy and guaranteed way for any library to 
manage a journal seems to be to transfer an existing publication from a commercial publishing operation to joint faculty-librarian management.

The library's responsibility is to provide hosting services; coordinate a supporting process; and, provide additional services such as persistent URLs, workflow streamlining, mark-up, file generation, facilitating print on demand and registering with directories, search engines and harvesters to increase visibility.

Xia (2009: 373) expands on the Canadian experience indicating that the publishing systems adopted by libraries with regard to academic journal publishing seem to satisfy all of their constituents. When comparing this form of publishing to lodging materials with institutional repositories, it would seem that the idea of the library publishing academic content seems to have been more readily accepted by researchers than that of lodging with repositories (Xia 2009). There is buy-in from those who have served as editors of journals published by traditional presses. From the faculty editor's point of view, the new model of scholarly communication is able to provide many more benefits than the traditional model of publishing: free access for readers (through libraries' web sites), inexpensive hosting (even though libraries have to pay the hosting costs) and convenient management (through an efficient eworkflow). The ordinary scholar as reader is attracted to this model by its openaccess component. It may also be that institutional administrators are pleased with the library publishing because it increases the visibility of their institutions.

It would seem that open access is a significant benefit to the author, the institution and the end user. Academic institutions, with capacity, have been probing and in many instances implementing open access practices. Stellenbosch University is such an institution, blazing a path in open access publishing in South Africa.

\section{Open access: the case of Stellenbosch University}

It is imperative for institutions of higher education to view open access against the backdrop of changing scholarship and scholarly communication. Lynch (2003) argues that institutions of higher education have overlooked, for at least a decade, opportunities to support the most innovative and creative research emanating from the institution to the detriment of both faculty members and the institutions themselves. Lynch (2003: 3) goes on to say that academic "faculties have been exploring ways in which works of authorship in the new digital medium can enhance teaching and learning and the communication of scholarship". Such innovations, he claims, "are essential to keeping scholarship vital and effective, and they must not only be supported but nurtured". Nurturing these innovations, he argues, "reaches to the core mission of universities, and to the core values of universities".

In the case of Stellenbosch University, the institution's commitment to open access is evident in the Strategic Plan for the Environment of the Vice Rector (Research) 
(Stellenbosch University 2011). This plan feeds into the institutional strategic plan. There is commitment from the institution to leave a scientific footprint on the African continent. Within the broad institutional strategic goal of 'growing the knowledge base' there is a strategic intervention of the Vice Rector (Research) which reads: "Supporting, developing and contributing to high-level scholarly publication output and sharing research data and results with the rest of the world, especially with researchers from the developing world". Within this strategic intervention there are two Library strategic actions in support of open access. These strategic actions are: "(1) establishing a central open access fund to support and facilitate the University's Open Access mandate and, (2) establishing an e-Repository Research system to ingest, preserve and disseminate the intellectual output of the Institution" (Stellenbosch University 2011).

Clearly, there is substantial support from SU for the adoption of open access activities. The Library at SU, like many other academic libraries nationally and internationally, initiated its open access strategy with the creation of an institutional repository. The primary purpose of the institutional repository was to capture, organise and disseminate the theses and dissertations output of the University. This starting point (that is, the creation of a repository for theses and dissertations) seems to have been the norm for most academic institutions both nationally and internationally.

\subsection{Institutional repository}

In 2007, Stellenbosch University, via its Senate, had taken the bold step of making it mandatory for graduating students to submit (as of 2008) all theses and dissertations into the repository. Even more significant is the acceptance by the University of ONLY a digital version of the thesis or dissertation - there is no requirement to submit a hardcopy. This mandatory submission of a digital copy of the thesis or dissertation was ground breaking as it was the first such practice in South Africa and most probably on the African continent.

The 'only digital version' policy (that is, no hardcopy version required) alludes to good preservation policy and practice. Unfortunately, the SU Library and Information Service does not currently have a long term preservation policy. The Library is currently reliant on the DSpace software which has localised preservation capabilities. Nonetheless, there are practices that ensure duplication through backup systems and disaster recovery. To ensure continuity in the event of disasters, there is a Unix back-up to two identical servers distributed between the Library and the SU's central IT Department. A third back-up is a tape format to the University's disaster recovery room which is located underground off campus.

In a parallel system aimed at developing long term preservation, the Library is currently engaging in discussions with the MetaArchive Cooperative. The MetaArchive Cooperative is an international digital preservation network composed 
of libraries, archives and other memory institutions. It has a preservation network of secure servers (referred to as 'caches') in four countries with forty-eight institutions actively preserving their digital collections in this network.

The MetaArchive Cooperative preserves a wide variety of data types and many genres of content, including electronic theses and dissertations, digital newspapers and archival material including datasets. The network is 'dark', in that access is limited to the content owner or contributor. The MetaArchive Cooperative secure network provides the necessary infrastructure to support the preservation of content in SU's institutional repository.

As an institution committed to sharing its research with the rest of the world, SU, through its Library and Information Service has invested in an eScholarship Office with the responsibility of exponentially growing the institution's repository. Like most other academic libraries, the repository at SU's Library and Information Service started out with the capture, organisation and dissemination of its theses and dissertations. The theses and dissertations repository (then called SUNeTD) grew exponentially as commitment from the University community to openly share institutional research output grew. This theses and dissertations repository grew into a much bigger repository now called SUNScholar. This repository (SUNScholar) is currently being populated with a much wider range of materials which includes inaugural addresses, conference proceedings and published journal articles.

Despite the acceptance of a wider range of material types, the priority is now populating the repository with published journal articles. In terms of populating the repository with these research articles, the Library has developed a populating strategy. The core principle of the strategy is to accelerate the populating of the repository with retrospective research articles. It is anticipated that in the future authors will, through a mandatory process, deposit a copy of their research articles in SUNScholar.

The strategy is broken down into three components or steps. The first step is to identify where (in which publications) SU staff are publishing their research. This step would assist in identifying publishing houses which are publishing a significant number of research articles emanating from Stellenbosch University. Information gathered from this process would allow the Library to select one publishing house (as a starting point) to solicit bibliographic data for the repository. This step would also reveal authors who are publishing in open access forums. In instances where authors are publishing in open access forums, the obstacles to uploading the full text research output into SUNScholar would be minimal. Hence, it would be possible to accelerate the populating of SUNScholar with research articles published in open access forums.

Step two in this strategy is broken down further. The first phase of step two is to collect the bibliographic details of the research output and the abstract (where 
possible) and to upload this into SUNScholar. The second phase would be to collect the corresponding full text articles and populate the repository with these full text articles, be it the published version or the author's post prints.

The third step would be to submit those articles, which have a range of restrictions attached to them, into SUNScholar. The Library would need to acquire copyright clearance, create appropriate metadata before making these research articles available to the national and international information seeking communities via the repository.

This is a very linear process which implies that other processes need to run parallel to this process to ensure acceleration in populating the repository with research articles. An example of a parallel process is using the SWORD ${ }^{1}$ protocol to automatically populate the repository with material from open access vendors such as BioMed Central. Further, authors would be encouraged to submit post prints directly into SUNScholar.

To enhance the visibility of the content in SUNScholar it would be registered with various harvesters such as Google, Google Scholar, OpenDOAR, Scopus Scirus, OCLC and IRSpace. The Open Archives Initiative develops and promotes interoperability standards that aim to facilitate the efficient dissemination of content (see http://www.openarchives.org/). These interoperability standards are referred to as the Open Archives Initiative Protocol for Metadata Harvesting (OAI-PMH). To be successfully harvested and for harvesters and search engines to retrieve and understand the metadata, it is important that the repository is OAI-PMH compliant and adheres to the Open Archives Initiative Protocol for Metadata Harvesting.

\subsection{Open access journal publishing}

Researchers at Stellenbosch University have two options when participating in open access publishing. The first is to publish with established 'for profit' publishers. The second option is to publish with 'not for profit' organisations. To support researchers who prefer to publish with 'for profit' vendors, the Library has created an 'open access publishing fund'. The Open Access Fund (now a budget item for the Library) is used to support SU researchers publishing in open access journals. This Fund would be used for:

- Subsiding author fees for publishing in open access journals;

- Taking up institutional memberships with Open Access publishers such as BioMed Central (BMC) and Public Library of Science (PLoS). Institutional membership endorses open access publishing and allows for the subsidising of author fees of Stellenbosch University researchers publishing in these journals; and,

- Subsidising author fees for publishing in regular journals where an additional fee is required to allow open access to an author's published article. 
A significant route in the second option is publishing research journals electronically using open source software. In support of this route, the Library (in 2010) began an exhaustive investigation into open source software that would assist in publishing research output electronically.

\subsubsection{Open Journal Systems (OJS)}

The process of publishing using open source software to share research output with as wide an audience as possible was a venture into unchartered territory for the Library. The Library, in collaboration with Stellenbosch University academic departments, began this venture with a pilot project of publishing scholarly journals using the open source software, Open Journal Systems (OJS). In venturing down this road, SU has become the first academic institution in South Africa and on the continent to formally offer its academic staff a comprehensive service to publish their research output using an open source publishing platform. Further, this collaboration between the Library and academic departments has assisted the SU Library and Information Service to contribute to a new chapter in African librarianship.

In must be emphasized that the rigor associated with academic publishing is not lost when publishing in this open access platform. In fact, the efficiency of publishing using the OJS process adds value to the academic process in that the administrative processes are kept to a minimum and the time delays associated with the administrative process in publishing are minimized.

During the investigative process it was found that the offerings of OJS, especially the workflow, fulfilled the publishing needs as per the terms of reference of the pilot project. The terms of reference were to test and implement an open access platform that was cost efficient, could be hosted by the Library and provided a workflow that was simple, efficient and effective. Further, the system must also be efficient in terms of turn-around time - from initial submission of the manuscript to eventual publication of the peer-reviewed manuscript.

\subsubsection{OJS as a system}

According to the Public Knowledge Project (PKP) (2011) document, OJS was designed to facilitate the development of open access and peer-reviewed publishing through an efficient and inexpensive editorial management workflow, including article submission, multiple rounds of peer-review, and indexing. OJS relies upon individuals fulfilling different roles, such as the journal manager, editor, reviewer, author, reader and such.

Of significant interest in OJS to the academic (bar the open access issue) is the editorial workflow which is considered the forte of OJS. 


\subsubsection{The editorial process}

The OJS management systems are structured around the traditional journal workflow which required moving a submission through reviewing, and if accepted, editing and publishing, with records maintained of who is doing what and when. OJS uses a prepared set of e-mails to contact the necessary people at each step, whether authors, editors, reviewers, copyeditors, or proofreaders. These e-mails, which are used to coordinate processes among editors, authors, reviewers, etc., contain the necessary information for each submission that is automatically filled in. The e-mail can be personalized by an editor prior to sending, except in such cases of automated reminders (PKP 2011).

A typical workflow scenario includes the editor-in-chief sending out a call for papers and authors submitting their work directly. Editors can drop into the journal's workspace to oversee the review process. Reviewers can pick up assigned papers and electronically post their reviews. Accepted papers are edited, laid out, published and indexed electronically.

\subsubsection{The adoption of OJS by Stellenbosch University}

After almost ten months of experimenting with OJS, the Library developed an efficient local infrastructure and developed concomitant procedures to support the publication of journals using OJS. On 24 October 2011 Stellenbosch University, via the Library, launched SUNJournals which is the host to the thirteen journal titles that are now published using OJS.

Some of the titles hosted by the Library include Scientia Militaria (Faculty of Military Science), Stellenbosch Papers in Linguistics (Department of Linguistics), Per Linguam (Faculty of Education), African Zoology (from the Zoological Society of Southern Africa) and Zambian Journal of Physiotherapy. Of the eleven titles, more than fifty percent are accredited by the Department of Higher Education and Training. Further, African Zoology is an ISI listed journal and has an impact factor of 1.018. In more recent discussions between the Library and information Association of South Africa (LIASA) and the Library, there was acceptance that SU will host the South African Journal of Libraries and Information Science.

The benefits of OJS for Stellenbosch University can be placed into two categories; firstly, those benefits that are tangible and secondly, those that are esoteric. In terms of the former, OJS is efficient in that it minimizes the turn-around time, that is, from submission of the article by the author through the review process, and to the eventual publication of the article. The editors have the option of publishing the articles individually (and then as an issue or volume) or as an issue.

Given that Stellenbosch University has been leading the process of academic institutions acting as open access publishers, SU made application for the 
registration of a domain name that was not institution specific. The domain name registered for its OJS project is journals.ac.za. This persistent URL (journals.ac.za) supports long term preservation even after the title has gone out of circulation.

Further, the Library is a registered member of CrossRef, an international body managing the distribution of unique Digital Object Identifiers (DOls). Each article published is assigned a DOI. The DOI ensures authenticity which reinforces the trustworthiness of the journal title. Further, CrossRef will also ensure that the DOls are harvestable by leading harvesting institutions.

The esoteric benefits of OJS for SU are associated with the increase in visibility of research content especially content from the developing world. It has been argued that critical content languishing in small libraries or offices of professors becomes available to the entire world. The use of the OJS to publish Stellenbosch University journals is best summarized by a leading researcher at SU who stated that "local journals that convey critical and relevant research material for the African context will now have exceptional visibility. In fact, the research output in these journals [local journals published via OJS] will potentially have greater visibility than any of the leading academic journals" (Van Wyk 2011).

Although OJS has subscription capabilities, the fundamental principle is that the content is openly accessible to the world's research population and society at large. This is in keeping with the principle that research be made available as a public good. There is sufficient evidence (Bevan 2007; Greig and Nixon 2007; Swan and Carr 2008) to show that open access radically improves the visibility of research content. The positives that can be gleaned from this improved visibility are the capacity to attract funds (including research funds), attract students of high caliber (including international students), and attract collaboration with the best researchers at national and international levels. Essentially, increased visibility means increased prestige for the institution and all that goes with it.

Publishing using OJS has benefits for both the seasoned researcher and the novice researcher. For the seasoned researcher, the quick publishing process without compromising scholarly integrity facilitates early publishing of the article, early discourse, peer feedback and such, all leading to new research and innovation. For novice researchers, it is an avenue to grow their research publication skills and to introduce them to a forum that is rigorous but more accommodating. The quick turnaround time would not dampen enthusiasm to publish.

\subsection{The significance of open access publishing for Stellenbosch University}

The Library at SU plays a significant role in managing a network of information streams including the 'in-stream' (that is, resources to produce research) and the 'out-stream' (publication models). It takes cognizance of the fact that open access to scientific knowledge would contribute to SU's strategic goal of expanding the 
knowledge base through, inter alia, the sharing of its research output and the growth of a new cadre of researchers. The Library makes every endeavour to ensure that the research output of the institution is made accessible to the international research community and society at large by supporting and/or publishing the institution's output in open access forums.

The research output that is published in open access forums described facilitates access to content that would ordinarily not be accessible to a substantial community of researchers. This opening up of access to relevant and essential content contributes to Africans finding solutions to problems that beset development of the continent. Given the synergies that exist between and among African counties, the visibility of local content promotes collaboration and finding innovative solutions. This collaboration augurs well for growing the institution's knowledge base through transferring of local knowledge and merging this knowledge with other knowledge streams to grow unique and specialized research communities.

\section{Conclusion}

Institutional repositories are fast becoming common place among academic institutions. Stellenbosch University is not exempt from this 'public good practice'. Like most other academic institutions, Stellenbosch University created its repository to capture, organise and disseminate its theses and dissertations output. The University, in subscribing to the principle that trusted and relevant information is critical for African development, probed the exploitation of available technology to open up access to its research output. Further, SU has as one of its strategic goals 'broadening the knowledge base', a segment of which entails leaving a scientific footprint on the African continent. The Library and Information Service of SU has played a significant role in contributing to this strategic goal of broadening the knowledge base by striving for 'repository excellence' and testing and implementing the publishing of journals using the open source software, OJS.

The Library is a strong advocate of open access facilitating the free flow of information which is fundamental to bridging the knowledge gaps between privileged and under-privileged communities. Further, open access contributes to social inclusion and economic empowerment as citizens have universal access to information and knowledge, ranging from public information to specialized or customized information related to one's profession, vocation or culture. The adoption of OJS as a publishing platform contributes significantly to making relevant, quality content available to the rest of South Africa and the African continent - giving veracity to the claim that Stellenbosch University is indeed leaving a scientific footprint on the African continent.

Despite the perceived success of the Library and Information Service in this new era of open access publishing, the authors are of the view that the road is never ending 
as new challenges and opportunities would present themselves and would need to be embraced. The challenge is no longer getting to the end of the road (for example, a perfect repository) but rather adopting new technologies and processes and practices to ensure maximum sharing of scholarly literature. The authors therefore conclude that reaching the end of the road is a negative outcome - the aspiration is to 'never get there'. Testimony of the benefit of not 'getting there' is the recent intention to expand SU's SUNScholar to include Open Educational Resources and to expand SUNJournals to include Open Conference Systems.

\section{$\underline{\text { Notes: }}$}

1. SWORD is a standard mechanism for depositing content into repositories and other systems. A standard deposit interface to repositories allows more services to be built which can offer functionality such as deposit from multiple locations, e.g. disparate repositories, desktop drag-n-drop tools or from within standard office applications. SWORD can also facilitate deposit to multiple repositories, increasingly important for depositors who wish to deposit to funder, institutional or subject repositories. Other possibilities include migration of content between repositories, transfer to preservation services and such (Brief history of SWORD 2011).

\section{$9 \quad$ References}

Adams, J., King, C. and Hook, D. 2010. Global research report: Africa. [Online]. Available: http://thomsonreuters.com/content/corporate/docs/globalresearchreportafrica.pdf. [Accessed 10 June 2011].

Akst, D. and Jensen, M. 2001. Africa goes online. [Online]. Carnegie Corporation of New York: Carnegie reporter, 1 (2). Available:

http://carnegie.org/publications/carnegie-reporter/single/view/article/item/14. [Accessed 30 May 2011].

Bevan, S.J. 2007. Developing an institutional repository: Cranfield QUEprints - a case study. OCLC systems \& services: international digital library perspectives, 23(2). [Online]. Available: http://www.emeraldinsight.com/1065-075X.htm. [Accessed 21 June 2009].

Blaxter, L., Hughes, C. and Tight, M. 2006. How to research. $3^{\text {rd }}$ ed. London: Open University Press.

Brief history of SWORD. 2011. [Online]. Available: http://swordapp.org/about/a-briefhistory/. [Accessed 24 October 2011].

Crow, R. 2002. The case for institutional repositories: a SPARC position paper. [Online]. Available: http://scholarship.utm.edu/20/1/SPARC 102.pdf. [Accessed 03 March 2010]. 
Fouche, C.B. 2005.Qualitative research designs. In De Vos, A.S., Strydom, H., Fouche, C.B. and Delport, C.S.L. Research at grass roots. $3^{\text {rd }}$ ed. Pretoria: Van Schaik. pp. 267-273.

Gorman, G.E. and Clayton, P. 2005. Qualitative research for the information professional: a practical handbook. London: Facet.

Gozetti, P. 2006. Institutional repositories in scholarly communication: a literature review on models, issues and current trends. MA/MSc International Information Studies, University of Northumbria. [Online]. Available: http://dspaceunipr.cilea.it/bitstream/1889/1156/1/Institutional\%20Repositories\%20in\%20Scholarly \%20Communication\%20a\%20literature\%20review\%20on\%20models\%20issues\%20 and\%20current\%20trends.pdf. [Accessed 24 October 2011].

Greig, M. and Nixon, W.J. 2007. On the road to enlightenment: establishing an institutional repository service for the University of Glasgow. OCLC systems and services: international digital library perspectives, 23(3). [Online]. Available: http://www.emeraldinsight.com/journals.htm?articleid=1622097\&show=abstract. [Accessed 04 August 2010].

Hahn, K.L. 2008. Research library publishing services: new options for university publishing. Washington, DC: Association of Research Libraries. [Online]. Available: http://www.arl.org/bm doc/research-library-publishing-services.pdf. [Accessed 02 March 2011].

Jeffrey, K.G. 2006. Open access: an introduction. ERCIM news, 64: 16-17. [Online]. Available: http://www.ercim.eu/publication0-/Ercim News/enw64/EN64.pdf. [Accessed 15 August 2011].

Kotecha, P., Walwyn, D. and Pinto, C. 2011. Deepening research capacity and collaboration across universities in SADC: a Southern African universities regional research and development fund. [Online]. Available:

http://www.sarua.org/files/publications/RDFund/SARU RD\%20Fund May\%202011 \%20Ver\%201.pdf. [Accessed 10 June 2011].

Lindegger, G. 2006. Research methods in clinical research. In Blanche, T.M., Durrheim, K. and Painter, D. Research in practice: applied methods for the social sciences. $2^{\text {nd }}$ ed. Cape Town: UCT Press. pp. 456-475.

Lor, P. 2007. Libraries in times of open access: paper presented at the APE 2007: Academic Publishing in Europe Conference "Innovation \& Publishing", Berlin, 23-24 January 2007. Information services and use, 27: 193-205. [Online]. Available: http://portal.acm.org/citation.cfm?id=1370647. [Accessed 14 October 2010].

Lynch, C.A. 2003. Institutional repositories: essential infrastructure for scholarship in the digital age. ARL: a bimonthly report, 226. [Online]. Available: 
http://www.arl.org/resources/pubs/br/br226/br226ir.shtml. [Accessed 14 October 2010].

Nwagwu, W.E. and Ahmed, A. 2009. Building open access in Africa. International journal of technology management, 45(1/2): 82-101.

Ondari-Okemwa, E. 2007. Scholarly publishing in sub-Saharan Africa in the twentyfirst century: challenges and opportunities. First Monday, 12(10). [Online]. Available: http://firstmonday.org/htbin/cgiwrap/bin/ojs/index.php/fm/article/viewArticle/1966/184 2. [Accessed 02 June 2011].

PKP: Public Knowledge Project. [2011]. [Online]. Available: http://pkp.sfu.ca/ojs documentation. [Accessed 14 April 2011].

Stellenbosch University. 2011. Strategic plan for the environment of the $V R(R) 2011$ 2016: prepared by the management team of the Vice Rector (Research). Unpublished institutional document.

Swan, A. 2006. What is new in Open Access. LIBER quarterly, 16 (3/4). [Online]. Available: http://eprints.ecs.soton.ac.uk/13638/. [Accessed 20 August 2008].

Swan, A. and Carr, L. 2008. Institutions, their repositories and the Web. [Online]. Available: http://www.sciencedirect.com.ez.sun.ac.za/science. [Accessed 24 October 2011].

Tise, E. 2011. Strengthening African higher education through the dissemination of research content: the role of the library. Paper presented at the Association of African Universities - Conference of Rectors, Vice Chancellors and Presidents of African universities. Stellenbosch May 30-June 3. [Online]. Available:

http://events.aau.org/userfiles/file/corevip11/presentations/strengthening he.pdf. [Accessed 08 June 2011].

Van Wyk, J.H. 2011. Email communication to Vice Rector (Research), 20 Apr. Stellenbosch University, Stellenbosch.

Xia, J. 2009. Library publishing as a new model of scholarly communication. Journal of scholarly publishing, 40 (4): 370-383. [Online]. Available:

http://130.102.44.247/login?uri=/journals/journal of scholarly publishing/v040/40.4.x ia.pdf. [Accessed 04 August 2010].

Zvavanyange, R. E. 2012. Leveraging African research output on global research platforms. [Online]. Available: http://africa.ypard.net/fr/node/20087. Access on 4 September 2012 